\title{
BURIED PIPE RESPONSE SUBJECTED TO TRAFFIC LOAD EXPERIMENTAL AND NUMERICAL INVESTIGATIONS
}

\author{
*Ahdyeh Mosadegh ${ }^{1}$ and Hamid Nikraz ${ }^{2}$ \\ ${ }^{1,2}$ Department of Civil Engineering, Faculty of Science and Engineering, Curtin University, Australia \\ *Corresponding Author, Received: 13 April 2017, Revised: 06 May 2017, Accepted: 10 June 2017
}

\begin{abstract}
In this paper, a flexible buried pipe response subjected to traffic load is investigated through laboratory experiments and numerical analysis. A series of laboratory tests and numerical simulations were carried out to investigate the impact of surface pressure and burial depth on the model response. Experimental tests were carried out using UTM25 to apply load on surface of a tank in which pipe was buried. Numerical simulations were conducted using the Finite Element Method, ABAQUS software to develop a better understanding of the pipe behavior. Results indicate that a good agreement between numerical and experimental test results was observed. In addition, experimental and numerical analysis reveal that increasing burial depth decreases pipe deflection, increases soil surface settlement and decreases pressure on pipe while increasing surface pressure increases all mentioned parameters. From all numerical and experimental results and using the Curve Fitting analysis in Matlab, equations were developed to predict soil surface settlement, pipe vertical diametric strain and pressure on pipe. Cumulative error analysis shows that all predicted parameters have less than $10 \%$ error.
\end{abstract}

Keywords: HDPE pipe, Traffic load, Laboratory tests, Numerical analysis, Finite element

\section{INTRODUCTION}

Since the dawn of civilization underground pipelines have been serving humans life to improve their standard of living. Pipelines are a common and reliable mode of transportation and in general they represent a small risk to human life and to the environment. However, they can be a big threat and can represent large capital cost when they fail. Based on available data from the U. S. Pipeline and Hazardous Materials Safety Administration (PMHSA 2011), the average damage cost arising from significant pipeline damage incidents over the past 10 years was more than $\$ 400 \mathrm{M} /$ year[1]. In many cases of failures those buried pipelines are subjected to traffic load. Therefore, a comprehensive research on pipe-soil interaction subjected to traffic loads to minimize costs of coming failures is needed.

Over past decades numerous experimental and numerical researches have been carried out to investigate the pipe-soil response due to either moisture change or geometrical condition, soil types and burial depth impact, ground condition and failure effects. However, the research effort on pipeline behavior due to traffic loads is limited and still is a challenging task. In recent years, some researches have been investigated the behavior of buried flexible pipe under traffic load through experimental approaches. In a recent research the behavior of pipe in a large scale soil chamber under surface load was investigated by KO and Kuwano in 2010[2]. They investigated the performance of surrounding soil and distribution of acting stress on the pipe by using load cells installed on PVC pipe. It was found that in loose sand pipe deformation was much greater than those in dense backfill. Tafreshi and Khalaj analyzed the behavior of a buried plastic pipe and soil surface changes under traffic load [3]. It was found that burial depth, amplitude of surface pressure and soil density dramatically affects pipe behavior. The results from this research showed that increasing burial depth increases soil settlement and decreases pipe deflection[4].

The use of finite element method to simulate problems in pipe soil interaction analysis was introduced by Culvert in 1976 and Heger in 1985. Since then, many numerical investigations have been carried out to investigate pipe-soil interaction using finite element methods. In recent years, Tavakoli and Moghaddas Tefreshi carried out a research on buried pipe response protected by combination of geocell and rubber mixers subjected to traffic load. They used a finite element package, FLAC to model cyclic behavior of pipe and surrounding soil $[5,6]$. A good agreement between numerical and experimental results was observed and results showed that the use of geocell and rubber mixture significantly reduces pipe deflection and soil surface settlement. Mosadegh and Nikraz in 2015 performed a parametric study with the use of ABAQUS on both 2D and 3D models to illustrate the impact of surface pressure, loading area, boundary conditions, pipe material properties, internal pressure and pipe-soil interaction properties on buried pipe response and soil surface settlement. Amongst all parameters, surface pressure, burial depth and loading area had the most significant 
impact on model response. In their research the impact of cycles was not considered and traffic load was applied on soil surface as the static load[7]. From the literature review, previous studies are limited to either experimental or numerical analysis. An experimental and numerical study both together investigating the impact of traffic load on buried pipe response is needed see also [4]

The specific aims of this study are to examine the response of buried pipeline subjected to traffic load considering changes in pipe deflection, soil surface settlement, and increase on earth pressure on pipe through experimental and numerical investigations. A series of tests were conducted to analyze the impact of traffic load and burial depth on model response through full scale tests. A numerical simulation of laboratory model was developed to analyze those parameters impact on model response parallel to experimental tests. Finally, a relationship between parameters to predict pipe behavior, and surface changes and pressure on pipe due to traffic load was developed.

\section{EXPERIMENTAL SETUP}

A testing tank was designed and built as a rigid steel box with the dimensions of the $700 \mathrm{~mm} \times 600$ $\mathrm{mm} \times 230 \mathrm{~mm}$ (700 mm in width in X direction, 600 in length in $\mathrm{Z}$ direction and 230mm in depth in $\mathrm{Y}$ direction) and its detail is shown in Fig.1. The tank was built in Curtin University for the purpose of this project. The selected sizes are due to limitation from load applying machine. UTM 25 was used to apply load on soil through a footing as load plate. The footing was modelled as a steel plate with the length of $220 \mathrm{~mm}$, width of $100 \mathrm{~mm}$ and thickness of $20 \mathrm{~mm}$.
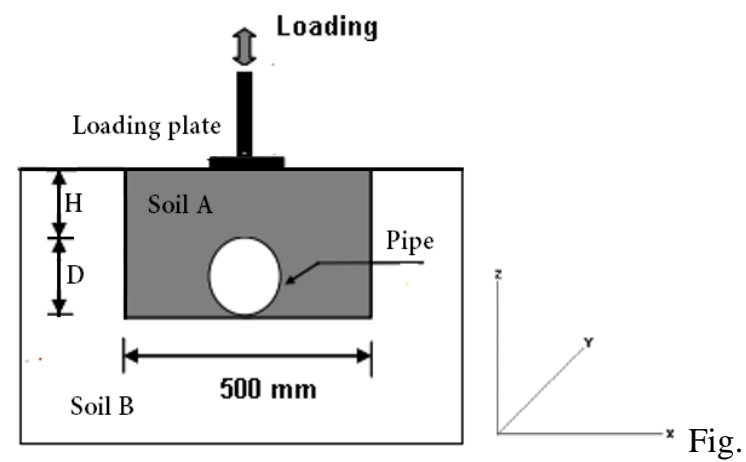

Fig.1. Schematic representation of test setup

The length of footing is almost equal to the width of the tank in order to maintain plain strain condition. For applying the load the footing is centred in the tank while the length of footing is parallel to the width of tank and buried pipe. It is noted that on the back face of tank a layer of smooth material was applied to decrease friction between soil and steel and make the friction similar to front face. Two types of soil used in this study, trench soil or soil A and granular soil or
Soil B as shown in Fig.2. Error! Reference source not found.Trench soil is a sandy soil with the grain size between 0.07 and $4.75 \mathrm{~mm}$ and its grain size distribution is shown in Fig. 2. Soil B or granular soil typically is used for flexible road bases with the grain size between 0.07 and 26. Soil A is classified as SP or poorly graded sand and soil B is classified as GP or poorly graded gravel based on the Unified Soil Classification System (USCS). The properties of both soil used in this research are shown in Table 1.

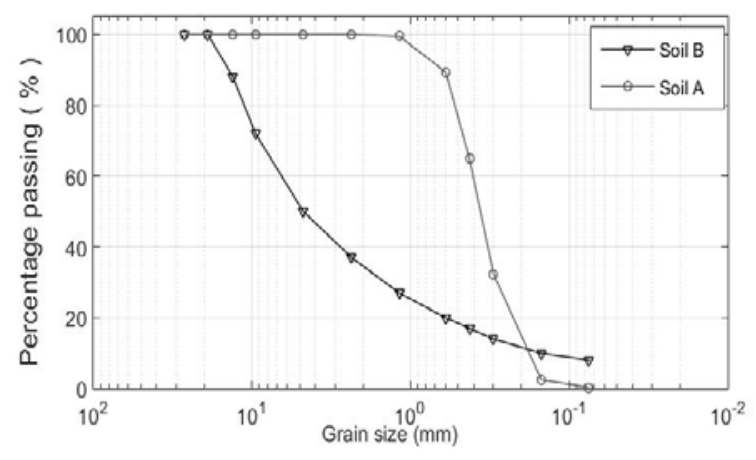

Fig. 2. Particle size distribution

Table 1 Physical properties of soils

\begin{tabular}{lll}
\hline Description & SoilA & SoilB \\
\hline $\mathrm{D}_{50}(\mathrm{~mm})$ & 0.32 & 4.7 \\
Coefficient of uniformity $\left(\mathrm{C}_{\mathrm{u}}\right)$ & 2.11 & 11.33 \\
Coefficient of concavity $\left(\mathrm{C}_{\mathrm{c}}\right)$ & 1.14 & 0.078 \\
Max. dry unit weight $\left(\mathrm{kN} / \mathrm{m}^{3}\right)$ & 16.5 & 20 \\
Optimum moisture $(\%)$ & 13 & 5 \\
\hline
\end{tabular}

The pipe was a $110 \mathrm{~mm}$ diameter HDPE or highdensity polyethylene pipe. It is noted in urban services such as drainage sewer applications, pipe diameters vary widely however, a reasonable dimension representing a common small pipe diameter has been chosen. The pipe has $6.8 \mathrm{~mm}$ thickness and $220 \mathrm{~mm}$ length with the Standard Dimension Ratio (SDR) or D/t of 16. Based on properties provided by manufacturer, envoiropipe, the pipe density is $955\left(\mathrm{~kg} / \mathrm{m}^{3}\right)$, its yield strength is 23 MPA and has a Young modulus of 950 MPA. The length of the pipe is $1 \mathrm{~cm}$ less than the width of tank to prevent binding against the end walls and boundary condition impacts. In addition, in order to prevent sand particles enter the pipe, the two ends of the pipe were covered by plastic as shown in Fig.3.

Tank sample for each test was prepared separately by placing granular soil or soil $\mathrm{B}$ at the bottom and lateral sides of tank in a U shape. Before putting the trench material, pipe should be in place while strain gauges and pressure cells were attached to the pipe in appropriate positions. Then, after placing pipe, soil A 
or sand material was to be placed and be compacted in trench area. The chosen trench width is $50 \mathrm{~cm}$ and this width was chosen according to AASHTO recommendation in which trench width should not be less than the greater of 1.5 times of the pipe outside diameter $(1 \mathrm{~m})$ plus $305 \mathrm{~mm}$ or the pipe outside diameter plus $406 \mathrm{~mm}$ [8]. Trench depth varied in different tests and changes between 220 to $385 \mathrm{~mm}$ which is sum of burial depth plus pipe diameter. Soil compaction was performed with an appropriate hammer to simulate compaction in the field to reach 95\% maximum dry density based on ASTM recommendations [9]. Height of the trench was divided into equal strips so that the soil in each layer (i.e. $6 \mathrm{~cm}$ thickness) was compacted separately. The soil weight required in each layer was calculated from considerations of soil unit weight and chamber's volume. At the end, the surface of soil was levelled. In the last step, loading cell and the loading plate were centred in the tank as shown in Fig. 3. An extra LVDT was placed on top of plate to monitor the surface settlement parallel to UTM25 data capturing. In the current experiment program, desired monitored data includes pipe deflection VDS, surface deformation SSS, increased vertical pressure distribution $\sigma$ on pipe soil interaction. Strain gauges used to capture pipe deflection were an F series Lead wire integrated foil strain gauge type: FLA-2-11 and manufactured by Tokyo Sokki Kenkyujo TML. They have the length and width of 2 and $1.5 \mathrm{~mm}$, respectively. Four of them were installed on pipe circumference. Later, it will be explained how strain gauges reading will be converted to pipe deflection. Soil surface settlement was monitored through two LVDTs, one built in UTM25 and the other provided on soil surface. To capture pressure on pipe, the pressure cells were Miniature Pressure Gauge type: PDA-1 MPA manufactured by Tokyo Sokki Kenkyujo with 6.5 $\mathrm{mm}$ diameter and $1 \mathrm{~mm}$ in thickness. Two pressure cells were placed on pipe crown for each test. It is noted the repeatability of tests to achieve reliable results were assessed prior to test program.

\section{NUMERICAL MODEL}

A numerical simulation was conducted and a FE model was built based on laboratory setup to investigate pipe-soil behaviour subjected to traffic load within numerical context.

The geometry of the model consists of three parts including pipe and two types of soil. As shown in m.at either ends of the mesh ( $\mathrm{y}=0$ and $\mathrm{y}=0.23 \mathrm{~m})$, all nodes are free in the y-direction and due to symmetry, only half of model is considered. The boundary conditions at the sidewalls are fixed in one direction and can move in $\mathrm{z}$ direction. Boundaries of the backfill part are changing from $1 \mathrm{D}$ to $2.5 \mathrm{D}$, in which $\mathrm{D}$ represents pipe diameter.
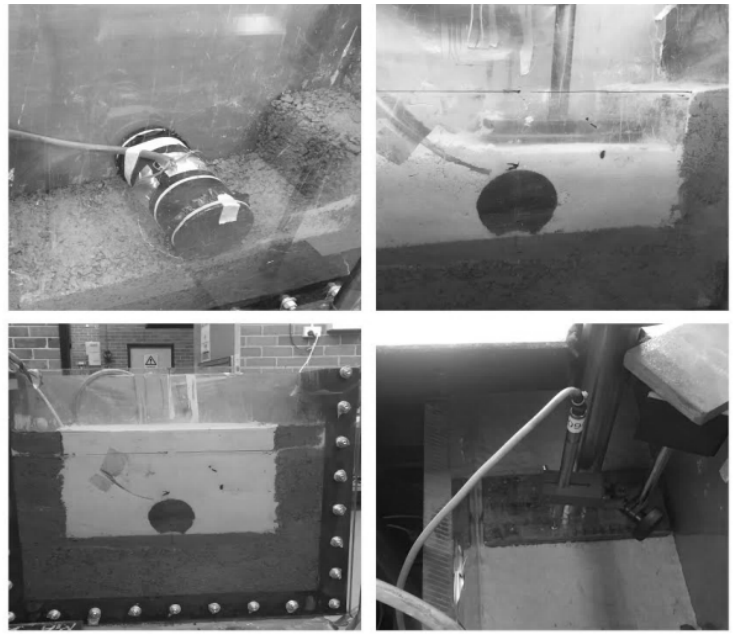

Fig. 3. Sample preparation from left to right and up to dawn: placing pipe; compacting trench; tank is ready, placing load plate and LVDT in place

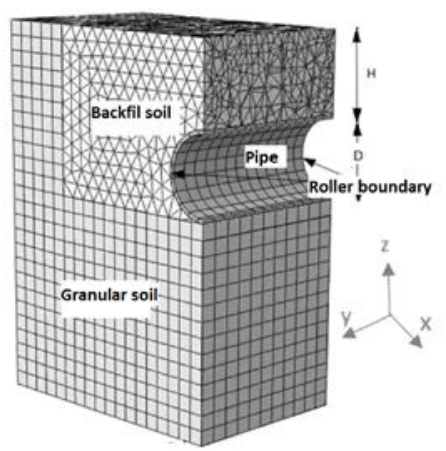

Fig. 4. Finite element discretization

The initial horizontal stresses are based on an arbitrary earth pressure coefficient of 0.4 . Threedimensional brick elements are used to simulate the surrounding soil (C3D8R) and four-node reducedintegration shell elements (type S4R) are used for the pipe. In all models, the mesh has been refined in areas with stress concentration around the pipe. Amongst different contact models available in ABAQUS, surface to surface interaction is chosen to model the interface between pipe and soil[10]. This interface can describe contact between two deformable surfaces or between a deformable surface and a rigid one. As the pipe is stiffer, it is simulated as a master surface and its surrounding soil as a slave surface. To avoid convergence difficulties, an unsymmetrical solver matrix is used to solve the problem as S-to-S discretization. Pipe is assumed to behave linear elastic and the properties of the HDPE pipe are adapted from provider as described earlier in section 2. To model soil material series of triaxial and direct shear tests were performed on trench soil and an elasto-plastic material law with Drucker-Prager failure criterion and a non-associated flow rule were considered to describe the behavior of dense sand. 
This soil has a friction angel of $38.5^{\circ}$ and cohesion of $5 \mathrm{kPa}$, Young's Modulus, E' of $9.8 \mathrm{MPa}$ and Poisson's Ratio, $\vartheta$ of 0.3 . As granular soil has less influence on test results its plasticity was not considered and it models a linear elastic with Young's Modulus, E' of $300 \mathrm{MPa}$ and Poisson's Ratio, $\vartheta$ of 0.4 . The model is created in four steps. In the first step, which is the initial condition, the pipe and soil initial conditions such as the boundary conditions and the interfaces between soil and pipe, have been defined. In the next step, geostatic step, a gravity load is applied to the model and an average initial soil stress state is applied throughout the soil mass prior to application of the surface load. In the third step, pipe and pipe-soil interaction are activated and the pipe weight is applied to the model. Pipe elements are reactivated during this step allowing movement in a vertical direction. In the last step, traffic load is applied to the soil surface at the trench width, exactly on top of the pipe acting over a rectangular of 0.2 length and 0.1 width immediately over the centreline of pipe.

It is essential to find a relationship between measured circumferential strain on pipe and pipe deflection. For that purpose a parallel plate test was carried out, as shown in Fig. 5, using a compression testing machine to measure vertical diametrical change of pipe (measured by LVDT) and wall circumferential strain at crown and bottom of pipe (measured by two strain gauges). Once the bedding is formed, pipe deflections can be calculated through measuring strain at SG s. To predict pipe behavior a FEM model was built to measure pipe deflection and strains. Pipe element type was a three- dimensional element shell elements (S4R) with reduced integration and fixed boundary condition on the bottom as shown in Fig. 5 . For validation, results obtained from experimental and numerical analysis were compared with those calculated from empirical method in Eq(1) [11]:

$\varepsilon=\frac{P D}{2 E t}+6\left(\frac{t}{D}\right) X\left(\frac{\Delta y}{y}\right)$

where $\boldsymbol{\varepsilon}$ is pipe strain, $\mathrm{P}$ is internal pressure, $\mathrm{D}$ pipe diameter, E Young Modulus of pipe, $t$ pipe thickness, and $\Delta y$ is total vertical diametric displacement of pipe. As there is no combined load and the pipe is under a compression load only, the first part of Eq(1) equals zero. Results of comparison between three methods are shown in Fig. 6 in which for six applied loads, the strain of pipe was calculated. It can be observed there is a good agreement among results obtained from different methods. In addition, a relationship between measured circumferential strain, CS, and pipe deflection, VDS, can be derived as $\operatorname{Eq}(2)$,

\section{VDS $=$ CS X 0.00045}
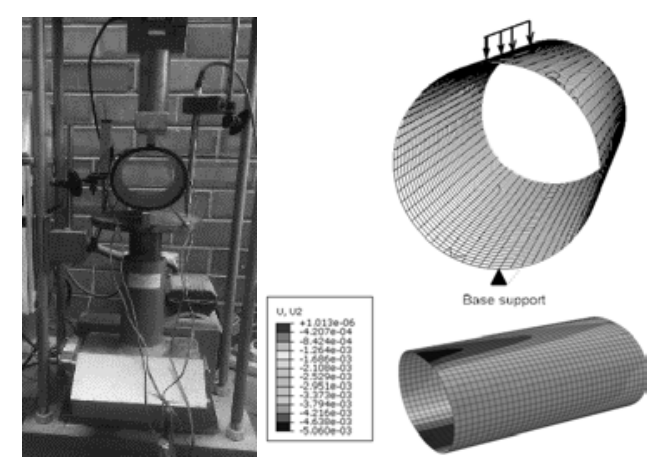

Fig. 5. (a) Applying pressure on pipe crown in vertical direction of pipe diameter in laboratory (left image) schematic view of $\mathrm{FE}$ results for pipe vertical displacement under load of $1400 \mathrm{~N}(600 \mathrm{kPa}$ ) (right image)

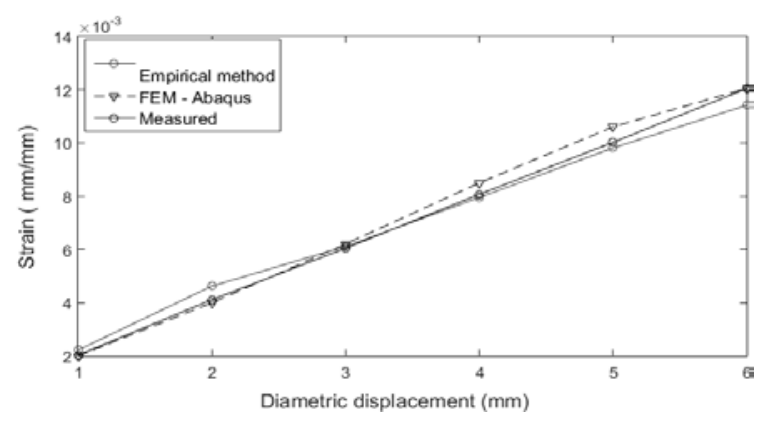

Fig. 6. Comparison of three methods

\section{RESULTS AND DISCUSSION}

In this section the results of numerical and experimental analysis of buried pipe are presented. First, the ultimate bearing capacity of loading plate on sand will be presented calculated through experimental and numerical investigations. Then, the impact of traffic load and influences of pressure magnitude and pipe burial depth on model response will be investigated, experimental test results followed by numerical investigations. Due to paper length limitation just a brief overview of experimental results and numerical modelling will be presented.

\subsection{Ultimate bearing Capacity}

In this section, the result of laboratory tests and finite element method to investigate the ultimate bearing capacity of loading plate is presented. The methodology of this section is adopted from literature review which is not explained here because of page length limitation[12, 13]. For bearing capacity analysis a downward load has been applied on top of the soil during 65 seconds to avoid sudden collapse of soil under footing. After applying pressure, foundation pressure will be increased up to failure point which will be bearing capacity term. Then after performing the test and simulation, experimental 
results will be compared with numerical analysis. From experimental results, when failure takes place, the slip surfaces under the footing and its sides can be identified as shown in Fig. 7-a and they have developed clearly from the edge of footing to the ground surface. The result of plastic shear at failure point of is illustrated in Fig. 7-b. Results show that there are three different distinct area zones under the footing at failure point: triangular zone immediately under the footing; two radial zones, and two Rankin passive zones [14]. The pressure-settlement curve of both analysis are shown in Fig. 7-c. It can be seen that there is a prominent peak of $550 \mathrm{kPa}$ for both graphs. Based on experimental results after a certain load, the vertical displacement increases even for a lower load. In general, although the numerical results do not fit completely with the experimental results, the results are in good agreement. Any discrepancy may be related to the chosen model for soil and foundation parameters, and differences between the boundary conditions in the numerical and experimental models.

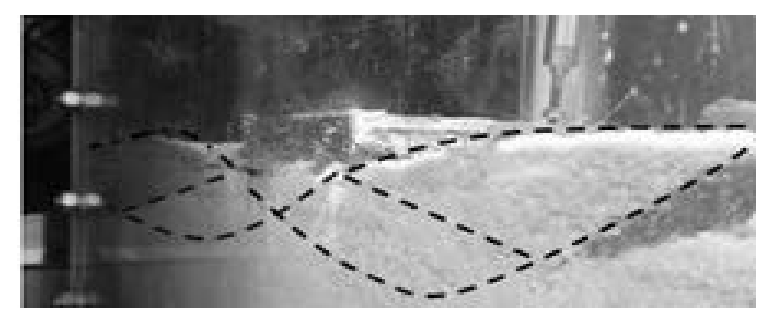

(a)

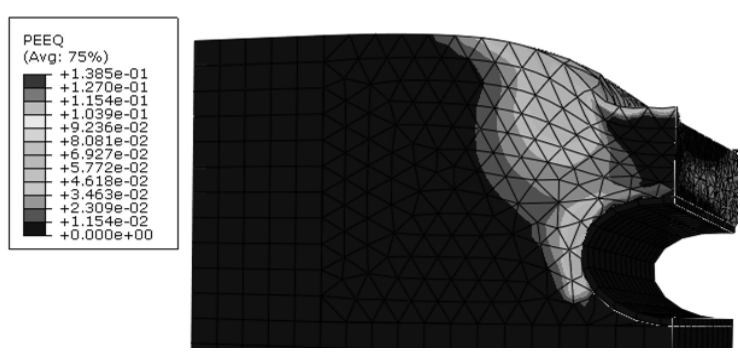

(b)

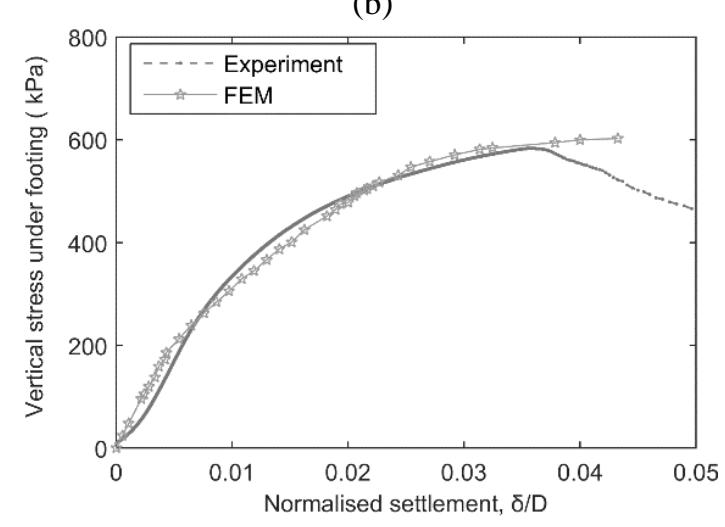

(c)

Fig. 7. (a) Bearing capacity failure (b) Plastic shear strain distribution at failure (c) Load-displacement curve comparison of FEM and experimental results

\subsection{Traffic Load}

Traffic load tests were performed to compare pipe behaviour due to change in surface pressure and burial depth during a static phase. In order to validate the FE model the results of numerical simulations will be compared with those from experimental results. It is noted the reason to apply traffic load as static load and not cyclic load is that the large portion of the pipe deformation and soil surface settlement occurs at the end of first cycle showing the importance of first cycle. In addition, performing static load is less time consuming compared with cyclic tests and simulations. Results of experimental tests for different surface pressure and burial depths are presented in Table 2 . All tests are simulated through finite element analysis and some of the calculated results will be presented in the following section.

Table 2 Values of VDS, SSS and $\sigma$ for different surface pressures and burial depths; experimental results

\begin{tabular}{llllll}
\hline $\begin{array}{l}\text { Test } \\
\text { No }\end{array}$ & $\begin{array}{l}\text { Surface } \\
\text { pressure }\end{array}$ & H/D & $\begin{array}{l}\text { VDS } \\
(\%)\end{array}$ & $\begin{array}{l}\text { SSS } \\
(\mathrm{mm})\end{array}$ & $\begin{array}{l}\sigma \\
(\mathrm{kPa})\end{array}$ \\
\hline 1 & 250 & 1 & 1.4 & 2.32 & 128 \\
2 & 250 & 1.5 & 1.09 & 2.99 & 90 \\
3 & 250 & 2.5 & 0.32 & 3.59 & 55 \\
4 & 400 & 1 & 1.86 & 3.65 & 225 \\
5 & 400 & 1.5 & 1.62 & 4.3 & 128 \\
6 & 400 & 2.5 & 0.95 & 5.9 & 78 \\
\hline
\end{tabular}

Fig. 8-a presents the numerical simulation of pipe displacement variation on its crown and along its circumference at two burial depths of $\mathrm{H}=1 \mathrm{D}$ and $\mathrm{H}=2.5 \mathrm{D}$ under surface pressure of $400 \mathrm{kPa}$. The value of zero on horizontal axis indicates the point on the crown at centre of loading. For example, for $\mathrm{H}=1 \mathrm{D}$ deflection at pipe crown is $1.8 \mathrm{~mm}$ and it decreases away from its centre and its value is minimum on the bottom of pipe plunged to almost zero. Both graphs converge on the bottom of pipe to zero which means under any surface pressure and burial depth pipe displacement on its bottom is minimum and is almost zero.

In Fig. 8-b the variation of surface settlement under loading area calculated through finite element method is illustrated. As it is shown maximum settlement for all burial depths occurs at pipe crown as expected. In addition, regardless of burial depth, the soil surface settlement decreases away from the centre of loading. It is clear that soil surface settlement for all burial depths converges to the minimum value over $2 \mathrm{~B}$ distance from centre or two 
times of loading area.

Fig. 8-c compares results obtained through experimental and numerical methods at $\mathrm{H} / \mathrm{D}=2.5$ for two surface pressures of 250 and $400 \mathrm{kPa}$. It can be seen that the value predicted with FEM analysis have a good agreement with those captured in laboratory at pipe crown. For example, at depth of $\mathrm{H}=2.5 \mathrm{D}$ under surface pressure of $400 \mathrm{kPa}$ PC on pipe crown shows pressure of $78 \mathrm{kPa}$ and FEM analysis predicts stress of almost $80 \mathrm{kPa}$. Maximum values of pipe deflection, soil surface settlement and pressure on pipe crown at any surface pressures and burial depths calculated through FE will be compared with experimental results summarised in Table 2 and will be discussed in the following section.

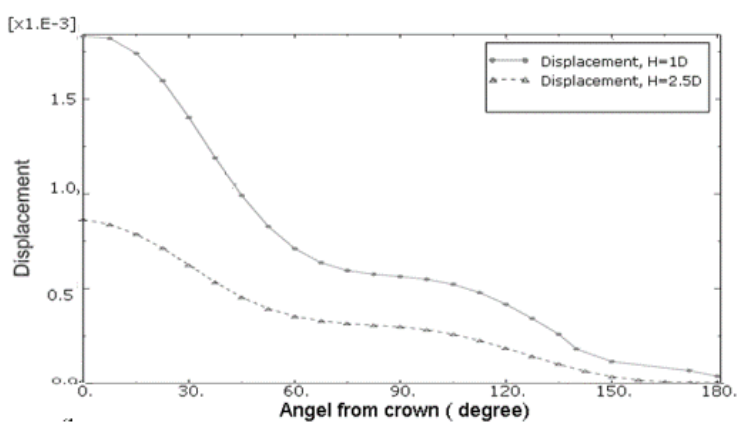

(a)

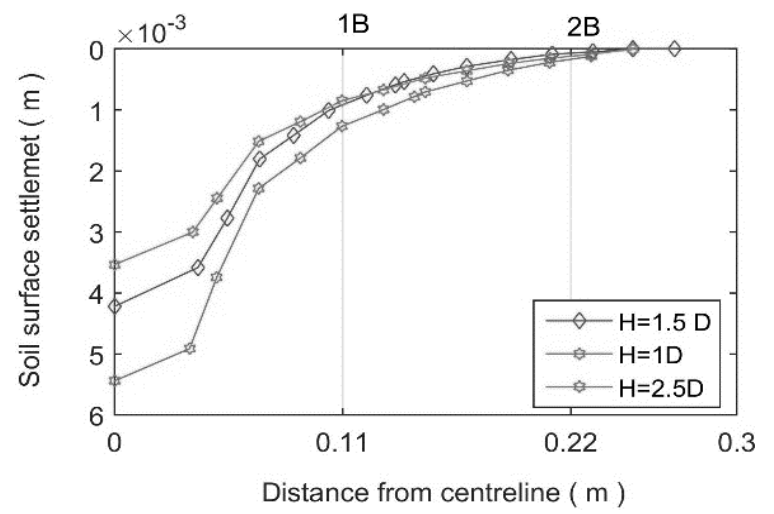

(b)

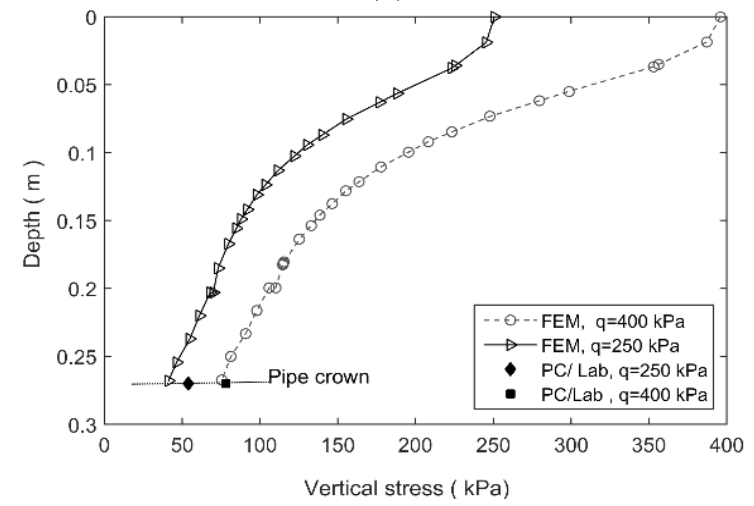

(c)

Fig. 8. FE results (a) pipe deflection (b) surface contours under surface pressure of $400 \mathrm{kPa}$ (c) vertical stress caused by the strip footing

\subsection{Comparison and Discussion of Results}

In this section, the results obtained from experimental tests and numerical simulations will be compared and the impact of burial depth and surface pressure on VDS, SSS and $\sigma$ variation will be discussed.

VDS: The impact of surface pressures of 250 and $400 \mathrm{kPa}$ and burial depths of $\mathrm{H}=1,1.5$ and 2.5D on pipe deflection is illustrated in Fig. 9. It can be seen that for both graphs increasing burial depth reduces VDS and maximum VDS occurs when burial depth is minimum. Increase in load pressure has a significant impact on change of VDS and increasing surface pressure increases VDS significantly. As illustrated, there is a good agreement between numerical and experimental results.

SSS: The influence of burial depth and surface pressure on soil surface settlement of model is illustrated in Fig. 9-b. As shown, for the specified surface pressure, SSS increases when burial depth increases. For example under surface pressure of 400 $\mathrm{kPa}$ at $\mathrm{H} / \mathrm{D}=1$, SSS is $3.05 \mathrm{~mm}$ and increasing burial depth from $\mathrm{H} / \mathrm{D}=1$ to 1.5 and 2.5, increases SSS from 3.05 to 5.1 and $6.8 \mathrm{~mm}$, respectively. This can be due to compressive layer above the pipe and with increasing burial depth the thickness of compressive layer increases. Means soil settles more when burial depth increases.

б: Fig. 9-c shows the impact of change in burial depth and surface pressure on stress transmit to the pipe crown obtained through experimental and numerical analysis. As illustrated results from two methods follow the same pattern and increasing burial depth leads to decrease in pressure on pipe crown. In addition, increasing surface pressure increases stress on the pipe as expected. The gap between two graphs for different surface pressures is lower for deeper burial depths means the impact of surface pressure is more significant for shallower pipes compared to deeper pipes.

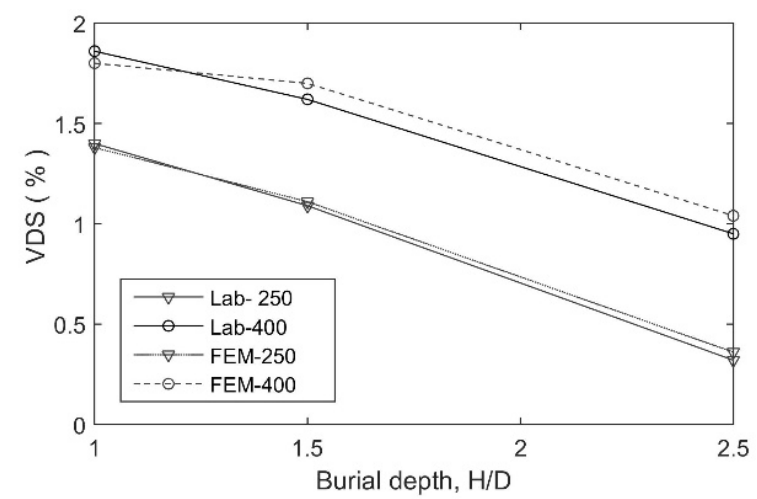

(a) 


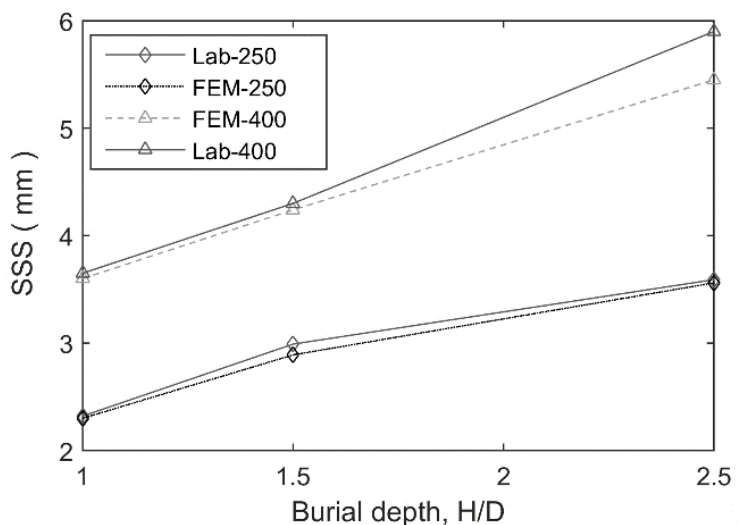

(b)

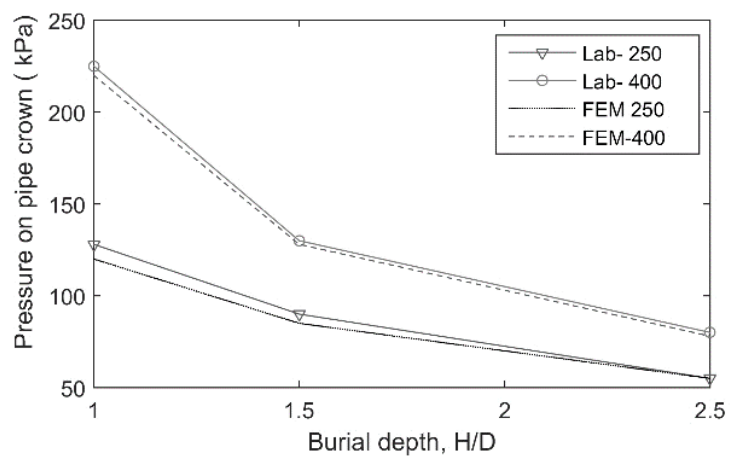

(c)

Fig. 9. (a) Variation of the maximum VDS of pipe (b) Soil surface settlement (c) earth pressure on pipe crown

\subsection{Regression model}

Based on experimental and numerical data, ration of soil surface settlement to pipe diameter, SSS/H, pipe vertical diametric strain, VDS, and stress on pipe crown to applied pressure, $\sigma / \mathrm{P}$ can be predicted as a function of pipe burial depth, H/D and magnitude of applied stress on soil surface, P. For this purpose, a regression model has been developed using Curve Fitting Toolbox in Matlab. This toolbox provides functions for fitting curves and surfaces to data and performs exploratory data analysis, pre-process and post-process data, compares candidate models, and removes outliers. After few trial and errors a linear polynomial model found to be best to predict model response. The function to fit a polynomial surface is $\mathrm{f}=$ fit ([x, y], z, 'poly23') or a degree 2 in $\mathrm{x}$ and degree 3 in $y$. So, the general equation to find a function between parameters will be:

$$
\begin{aligned}
& f(x y)=p 00+p 10 * x+p 01 * y+p 20 * \\
& x^{\wedge} 2+p 11 * x * y
\end{aligned}
$$

Where $\mathrm{x}$ and $\mathrm{y}$ are predictors variables while $\mathrm{x}$ is burial depth, $H / D$, and $y$ is magnitude of surface pressure to minimum pressure, $\mathrm{P} / \mathrm{P}_{0}$. It is noted the equation is normalised using dimensionless values for pressure and surface settlement diving them by initial pressure and depth of pipe, respectively. From all tests and finite element analysis the partial regression coefficients (p00, p10, p01, p20 and p11) are calculated and are illustrated in Table 3 . It is noted Rsquare of VDS, SSS/H and $\sigma / \mathrm{P}$ are 0.9959, 0.9899 and 0.9842 , respectively.

Table 3 Coefficients of regression model

\begin{tabular}{lccccc}
\hline Prediction & P00 & P10 & P01 & P20 & P11 \\
\hline VDS & 1.11 & -0.33 & 0.54 & -0.16 & 0.22 \\
SSS/H & 0.15 & -0.15 & +0.22 & 0.04 & -0.04 \\
o/P & 0.98 & -0.70 & 0.14 & 0.17 & -0.08 \\
\hline
\end{tabular}

The predicted values for VDS, SSS and $\sigma$ were calculated based on developed equations and for each value the accuracy of parameter was assessed based on percentage of error calculating through $\mathrm{Eq}(4)$

$$
\boldsymbol{E} \boldsymbol{p}=\left(\frac{\boldsymbol{A}_{i}-\boldsymbol{A}_{\boldsymbol{p}}}{\boldsymbol{A}_{\boldsymbol{i}}}\right) \mathrm{X} 100
$$

In which Ep is error percentage for both experimental and numerical analysis. $A_{i}$, is observed value of experimental test or numerical analysis and $A_{p}$ is predicted value at each test series. In order to show the precision of predicted results, the cumulative histogram percentage of errors of the model for the prediction of SSS/H, VDS and $\sigma / \mathrm{P}$ for data are shown in Fig.10. It shows that for predicted parameters, for example, $80 \%$ of data have less than $6 \%$ error for SSS while this error for VDS is 6\% and for $\sigma$ is $10 \%$.

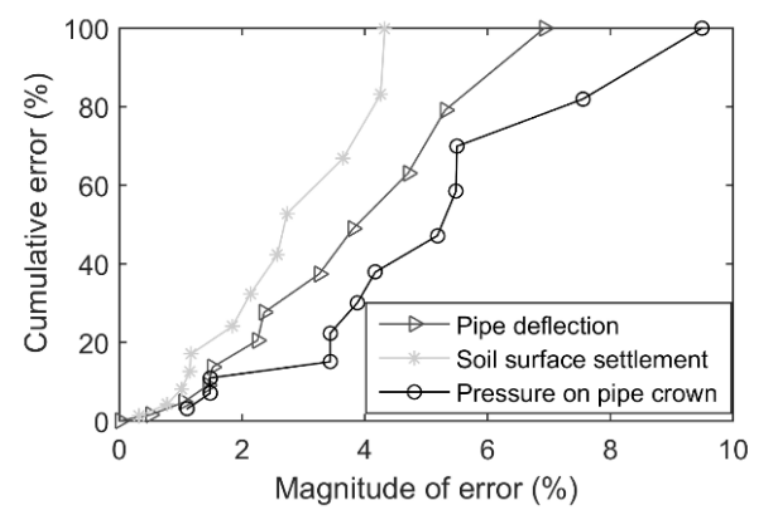

Fig. 10. Cumulative histogram percentage of error for the prediction of SSS, VDS and $\sigma$

\section{CONCLUSION}

In this research, an experimental and numerical analysis were carried out to investigate the impact of 
pipe embedment depth and surface pressure on buried pipe response under traffic load. Two test series were performed (1) the ultimate bearing capacity of soil (2) traffic load tests to simulate traffic load on buried pipe. Numerical simulations were performed to better understand model behaviour under different conditions. The main conclusions through this study can be summarised as follows:

- Good agreement between numerical and experimental test results was observed for both test series.

- The results from experimental investigation and numerical simulations indicates that the ultimate bearing capacity of footing was almost $570 \mathrm{kPa}$ for both analysis.

- Traffic test results reveal that pipe burial depth has a significant effect on surface settlement. Soil surface settlement increases as pipe burial depth increases. Increasing burial depth reduces pressure on pipe crown as well as pipe deflection.

- In addition, increasing surface pressure had a significant impact on increasing pipe deflection, soil surface settlement and pressure on pipe as expected.

- Regression model to estimate vertical diametric strain VDS and settlement of soil surface SSS and pressure on pipe crown $\sigma$ was developed based on all numerical and experimental tests data.

- Cumulative error show that all predicted values have less than $10 \%$ error.

- To provide further understanding of the behavior of buried pipes in response to external cyclic loading, this research could be extended in cyclic phase.

- In addition, the current study in experimental section was in the laboratory only and a full scale field verification is still needed.

\section{ACKNOWLEDGMENT}

The first author is the recipient of APPA-CUPS Scholarship of Curtin University. This support is highly acknowledged. The authors acknowledge help of Mark, Arne, Darren and Mirzet to run equipment and prepare samples at geotechnical laboratory of Curtin.

\section{REFERENCES}

1. Pipeline incident,. Pipeline Failure Causes. 2003.

2. Ko, D.H. and R. Kuwano, Model tests on behaviour of buried pipe in a large soil chamber , 2010 , London Taylor and Francis group, 2010: p. 625-631.

3. Moghaddas Tafreshi, S.N. and O. Khalaj, Analysis of repeated-load laboratory tests on buried plastic pipes in sand. Soil Dynamics and Earthquake Engineering, 2011. 31(1): p. 1-15.

4. Cao, Z., et al., Road surface permanent deformations with a shallowly buried steel-reinforced high-density polyethylene pipe under cyclic loading. Geotextiles and Geomembranes, 2016. 44(1): p. 28-38.

5. Tavakoli Mehrjardi, G., S.N. Moghaddas Tafreshi, and A.R. Dawson, Combined use of geocell reinforcement and rubber-soil mixtures to improve performance of buried pipes. Geotextiles and Geomembranes, 2012. 34: p. 116-130.

6. Tavakoli Mehrjardi, G., S.N. Moghaddas Tafreshi, and A.R. Dawson, Numerical analysis on Buried pipes protected by combination of geocell reinforcement and rubber-soil International Journal of Civil Engineering, 13 (2). , 2016. 13(2): p. 90-104.

7. Mosadegh. A and Nikraz. H. Finite Element Analyses of Buried Pipeline Subjected to Live Load Using ABAQUS. in Geoquebec conference. Sep 2015. Quebec City, Canada

8. AASHTO, American Association of State Highway and Transportation Officials (AASHTO). 1998: Washington DC USA.

9. ASCE, Guidelines for the Design of Buried Steel Pipe. 2001, americanlifelinesalliance.

10. ABAQUS-6.13, ABAQUS/CAE User's Manual. 2013, Dassault Systèmes: USA.

11. Moser, A.P., Buried Pipe Design, 2nd Edition. 2001: Mcgraw-hill.

12. Moayed, Z., R. R, and I. E., Evaluation on Bearing Capacity of Ring Foundations on two-Layered Soil. World Academy of Science, Engineering \& Technology, 2012(61): p. 1108.

13. Mosadegh, A. and H. Nikraz, Bearing Capacity Evaluation of Footing on a Layered - Soil using ABAQUS. Earth Sci Clim Change 2015 6(3): p. 1-8.

14. Terzaghi. K. and P. R.B., Soil Mechanics in Engineering Practice. 1948.

Copyright (c) Int. J. of GEOMATE. All rights reserved, including the making of copies unless permission is obtained from the copyright proprietors. 